УДК 005.334(075.8)

\title{
СПЕЦИФИКА УЧЕТА И УПРАВЛЕНИЯ РИСКАМИ ЭНЕРГЕТИЧЕСКИХ ПРЕДПРИЯТИЙ
}

\author{
Т.Ф. МАНЦЕРОВА \\ канд.экон.наук, доцент, заведующий кафедрой «Экономика и организация энергетики», \\ Белорусский национальный технический университет, г. Минск
}

\section{Е.И. ТЫМУЛЬ}

аспирант Белорусского национального технического университета, г. Минск

\begin{abstract}
Аннотация
Постоянное развитие экономики приводит к необходимости формирования качественно новой системы управления предприятием, адаптированной к условиям риска и неопределенности. В статье рассмотрены основные вопросы управления рисками с учетом специфики деятельности энергетических предприятий. Изложены основные отраслевые особенности проявления рисков и их анализа. Обоснована необходимость разработки методик и инструментов для выявления и снижения всех видов рисков на энергетических предприятии с учетом специфики функциионирования.
\end{abstract}

Continuous development of the economy leads to the necessity of forming a qualitatively new enterprise management system, adapted to the conditions of risk and uncertainty. The article deals with the main issues of risk management, taking into account the specifics of the energy companies. It is given the basic differences between manifestations of risks and their analysis. It is substantiated the necessity of development of methods and tools for identifying and reducing all kinds of risks in the energy company-specific operation.

\section{ВВЕДЕНИЕ}

Тенденции, которые можно наблюдать на мировой экономической арене, явно свидетельствуют о том, что в настоящее время управление рисками - это жизненно необходимое умение для выживания любой организации. Республика Беларусь в последние десятилетия держит уверенный курс к новой экономике. Такой переход от государственного контроля к рыночной конкуренции неизбежно приводит к новым «правилам игры». Конкурентный рынок требует умения распознавать риски и управлять ими.

\section{РЕЗУЛЬТАТЫ И ИХ ОБСУЖДЕНИЕ}

Исследование влияние различных рисков на функционирование организаций ведется на протяжении многих лет. Однако до сих пор не существует единого подхода к определению понятия «риск».

Для того чтобы лучше понять сущность риска, необходимо обратиться к этимологии слова «риск».

Источником термина risk могут служить несколько древних слов из разных европейских языков:

- французские risque (сомнительный) и risdoe (угроза, рисковать);

- итальянские risiko (опасность, угроза) и risicare (посметь, отважиться);

- греческое ridsikon, ridsa (скала, утес; объезжать скалу, утес);

- латинское rescum, обозначающее непредсказуемость, опасность или то, что разрушает.

В Европе термина «risk» встречается в средневековых источниках и главная сфера его применения - мореплавание и морская торговля. Отсюда одно из первоначальных значений глагола рисковать - объезжать утес, скалу, лавировать между скал.

Понятие риска в теорию рыночных отношений впервые ввел французский экономист Р. Кантильон, который рассматривал риск как свойство любой торговой деятельности, ведущейся по правилам конкуренции. Прибыли и потери торговца он оценивал как следствие неопределенности и риска.

Экономическая наука представляет классическую и неоклассическую теории предпринимательского риска. Классическая теория предпринимательского риска, у истоков которой стояли Дж. Милль и И.У. Сениор, отождествляет риск с математическим ожиданием потерь из-за выбора того или иного решения, т.е. риск представляет собой ущерб вследствие осуществления данного решения.

В 30-е годы ХХ в. экономисты А. Маршалл и А. Пигу разработали основы неоклассической теории предпринимательского риска, суть которой заключается в том, что предприниматель, отдавая предпочтения одному из альтернативных решений, должен руководствоваться двумя критериями: величиной ожидаемой прибыли и размерами ее возможных колебаний вокруг среднего значения. [1]

Перечисленные подходы ни в коей мере не учитывают фактора личного отношения предпринимателя к риску. Впервые свое внимание на этот факт обратил внимание Дж. М. Кейнс. Он пишет об «издержках риска» и их покрытии и считает целесообразным учитывать в экономических процессах три основных вида рисков: риск предпринимателя или заемщика, риск кредитора и риск, связанный с возможным уменьшением ценности денежной единицы. [2] 
Современные исследователи также уделяют внимание категориям неопределенности и риска. Анализ источников, посещенных понятиям «риск» и «риск-менеджмент», позволил выделить несколько основных подходов к трактовке данных понятий:

1) Опасность или угроза: риск - возможность наступления события с негативными последствиями, приводящими к вреду для человека или организации, т.е. риск - это возможность реализации предполагаемой опасности.

Риск-менеджмент в этом случае - уменьшение вероятности наступления негативных событий и (или) последствий от них с помощью мероприятий, которые требуют разумных затрат.

2) Возможность: риск - это «действие на удачу в надежде на счастливый случай». Предполагается, что чем выше риск, тем выше потенциальный доход.

В этом случае риск-менеджмент предполагает использование техники максимизации дохода при одновременном ограничении или минимизации потерь.

3) Неопределённость: риск - мера несоответствия между различными результатами решений, которые оцениваются через их полезность, вредность и эффективность по критериям соответствия выбранным ориентирам. [3]

Как отмечалось ранее, для каждой организации очень важно разработать стратегию управления возможными рисками, поэтому необходимо дать конкретные ответы на следующие вопросы:

1. какие именно виды рисков организация обязана учитывать в своей деятельности;

2. какие способы и инструменты позволяют управлять этими рисками;

3. какой объем рисков организация может взять на себя (приемлемая сумма убытка, которая может быть погашена из собственных средств).

Таким образом, стратегия управления рисками основывается на классификации рисков и выделении из общего списка наиболее значимых для организации данного вида экономической деятельности.

Существуют различные подходы к классификации рисков. Наиболее распространенной и, на наш взгляд, довольно полной является классификация, изложенная Балабановым И.Т. [4]

Риски в зависимости от возможного результата (рискового события) принято делить на две группы: чистые и спекулятивные (рисунок 1).

Чистые риски определяются возможностью получения отрицательного или нулевого результата (природноестественные, экологические, политические, транспортные и часть коммерческих рисков: имущественные, производственные, торговые).

Спекулятивные риски означают получение как положительного, так и отрицательного результата.

При рассмотрении рисков следует учитывать причины возникновения рисков (базисный или природный риск) и поэтому принято выделять следующие категории: природно-естественные, экологические, политические, транспортные, коммерческие риски.

Природно-естественные риски - это риски, связанные с проявлениями стихийных сил природы, например землетрясениями, наводнениями, бурями, пожарами, эпидемиями и т. п.

Экологические риски - это риски, связанные с загрязнением окружающей среды.

Политические риски связаны с политической ситуацией в стране и деятельностью государства. Эти риски появляются из-за нарушения условий производственно-торгового процесса по причинам, не зависящим от хозяйствующего субъекта.

Политические риски возникают:

$\checkmark$ из-за невозможности осуществления хозяйственной деятельности по причине военных действий, революции, обострения внутриполитической ситуации в стране, национализации, конфискации товаров и предприятий, введения эмбарго

$\checkmark$ отказа нового правительства выполнять принятые предшественниками обязательства и т. п.;

$\checkmark$ введения отсрочки (моратория) на внешние платежи по причине различных обстоятельств (забастовки, война и т. д.);

$\checkmark$ неблагоприятного изменения налогового законодательства;

$\checkmark$ запрета или ограничения конверсии национальной валюты в валюту платежа.

Транспортные риски - это риски, связанные с перевозкой грузов транспортом (автомобильным, морским, речным, железнодорожным, воздушным и т. д.).

Коммерческие риски являют собой опасность потерь в процессе финансово-хозяйственной деятельности. Они появляются вследствие неопределенности результатов от данной коммерческой сделки. Коммерческие риски делятся по структурному признаку на имущественные, производственные, торговые, финансовые.

Имущественные риски связаны с вероятностью потерь имущества хозяйственной единицы из-за кражи, диверсии, халатности, перенапряжения технических и технологических систем и т. п.

Производственные риски связаны с убытком от остановки производства вследствие воздействия различных факторов и прежде всего с уничтожением или повреждением основного и оборотного капиталов. К ним относятся также риски, связанные с внедрением в производство новой техники и технологий.

Торговые риски появляются из-за убытков по причине задержки платежей, отказа от платежа в период транспортировки товара, непоставки товара и т. п. 


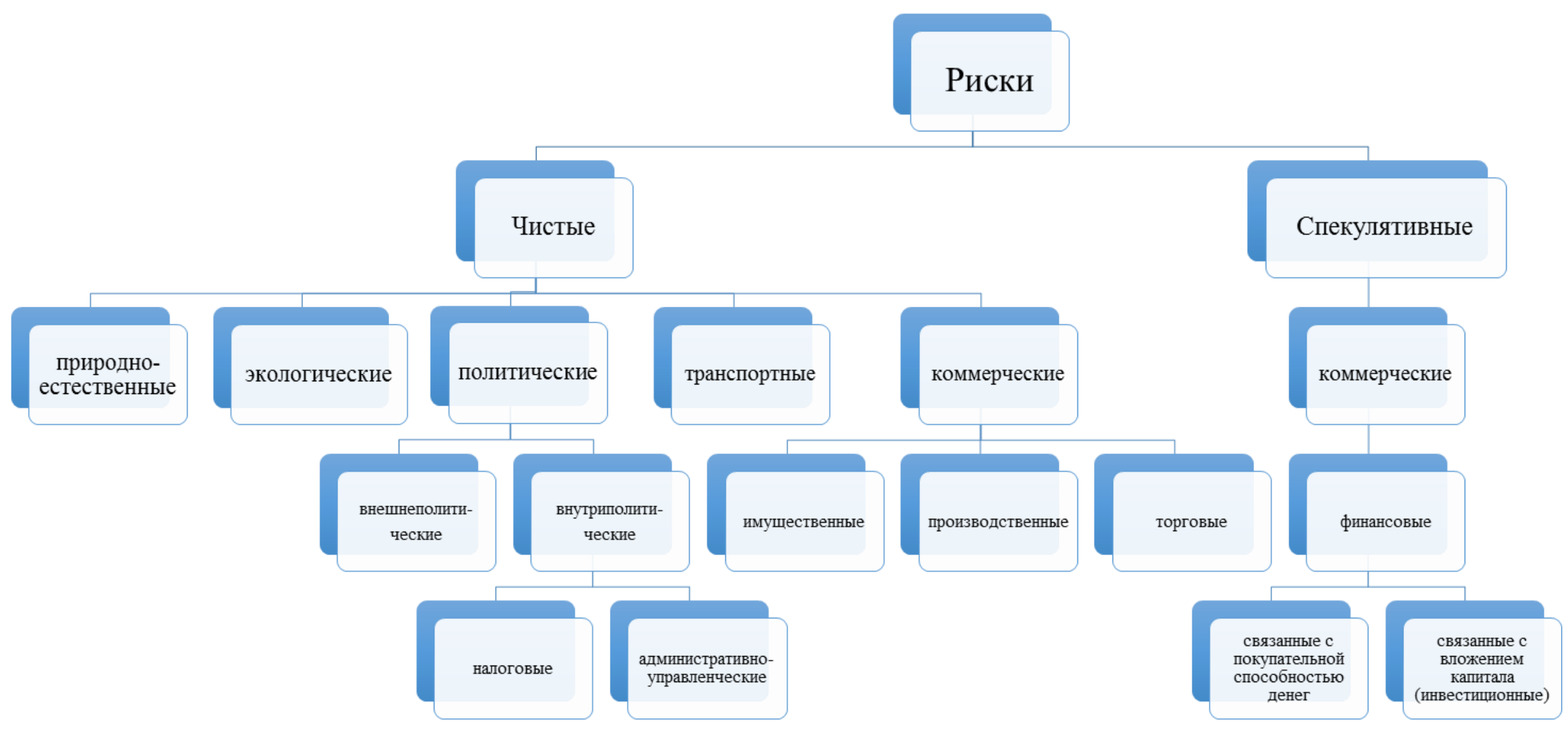

Рисунок 1 - Общая классификация рисков 
Финансовые риски появляются из-за вероятности потерь денежных средств. Они подразделяются: на риски, связанные с покупательной способностью денег, и риски, появляющиеся из-за вложения капитала (инвестиционные риски) (рисунок 2).

Риски, связанные с покупательной способностью денег - это инфляционные и дефляционные риски, валютные риски, риски ликвидности.

Инфляционный риск появляется из-за того, что при росте инфляции, получаемые денежные доходы обесцениваются с точки зрения реальной покупательной способности быстрее, чем растут, и поэтому у предпринимателя растут потери.

Дефляционный риск - результат того, что при росте дефляции происходит падение уровня цен, ухудшение экономических условий предпринимательства и снижение доходов.

Валютные риски означают опасность потерь, связанных с изменением курса одной иностранной валюты по отношению к другой при проведении внешнеэкономических кредитных и других валютных операций.

Риски ликвидности связаны с возможностью потерь при реализации ценных бумаг или других товаров из-за изменения их качества и потребительской стоимости.

Инфляционные риски состоят из следующих подвидов рисков: риск упущенной выгоды, риск снижения доходности, риск прямых финансовых потерь.

Риск упущенной выгоды является следствием наступления косвенного (побочного) финансового ущерба (неполученная прибыль) в результате неосуществленного какого-либо мероприятия (например, страхование, хеджирование, инвестирование и т. д.).

Риск снижения доходности может появиться из-за уменьшения размера процентов и дивидендов по портфельным инвестициям, по вкладам и кредитам.

Портфельные инвестиции появляются при формировании инвестиционного портфеля и представляют собой приобретение ценных бумаг и других активов. Портфель - совокупность ценных бумаг, имеющихся у инвестора.

Риск снижения доходности включает процентные риски и кредитные риски.

Процентные риски появляются вследствие опасности потерь коммерческими банками, кредитными учреждениями, инвестиционными институтами и т. д. в результате превышения процентных ставок, выплачиваемых ими по привлеченным средствам, над ставками по представленным кредитам. Такими рисками являются риски потерь, которые могут понести инвесторы в связи с изменениями дивидендов по акциям и изменениями процентных ставок на рынке по облигациям, сертификатам и другим ценным бумагам.

Кредитный риск появляется из-за опасности неуплаты заемщиком основного долга и процентов, причитающихся кредитору.

Риски прямых финансовых потерь - это биржевой риск, селективный риск, риск банкротства и кредитный риск.

Биржевые риски возникают из-за опасности потерь от биржевых сделок (риск неплатежа по коммерческим сделкам, риск неплатежа комиссионного вознаграждения брокерской фирмы и т. п.).

Селективные риски возникают из-за неправильного выбора видов вложения капитала, вида ценных бумаг для инвестирования в сравнении с другими видами ценных бумаг при формировании инвестиционного портфеля.

Риск банкротства появляется в результате неправильного выбора вложения капитала, полной потери предпринимателем собственного капитала и неспособности его рассчитываться по взятым на себя обязательствам.

Согласно проведенного опроса среди руководителей предприятий, проведенному аналитиками Национального банка Республики Беларусь в 2014 году, было установлено, что большая часть опрошенных считает основными видами рисков коммерческие риски (изменения спроса, цен, процентных ставок, валютного курса, возникновения неплатежеспособности и т.д.). Удельный вес данной группы рисков среди опрошенных респондентов составил 59,5\%. На усиление рисков, связанных с изменением в законодательстве, указали 13,8\% опрошенных. Расширение так называемых административно-управленческих рисков отметили 21,2\% участников опроса. Таким образом, можно сделать вывод о том, что наиболее перспективной группой рисков для совершенствования методов управления ими, являются именно финансовые риски.

Величина и влияние того или иного риска на хозяйственную деятельность предприятия в значительной степени зависит от отраслевой специфики функционирования предприятия.

Энергетика - это один из основных видов экономической деятельности, который производит тепловую и электрическую энергию, необходимую для функционирования любого предприятия, а также для жизнедеятельности населения.

До недавнего времени энергетика Республики Беларусь была выстроена по советскому принципу полной государственной монополии. Изменения в экономике нашей страны, которые происходят в последние десятилетия, привели к тому, что энергетика больше не может работать по старым правилам. Уход от перекрестного субсидирования и снижение государственной поддержки при одновременном переходе к рыночным отношениям - вот единственный выход для улучшения сложившейся ситуации. Однако, новые правила рынка приведут к возникновению значительного количества различных рисков.

Если говорить о чистых рисках, то наибольшее значение для энергетических предприятий могут иметь природно-естественные, транспортные и производственные риски, так как каждый из этих рисков может привести к перебоям в работе предприятия энергетики. Природно-естественные риски невозможно контролировать. Единственным выходом является грамотный учет данных рисков на стадии проектирования как самих станций, так и электрических и тепловых сетей. 


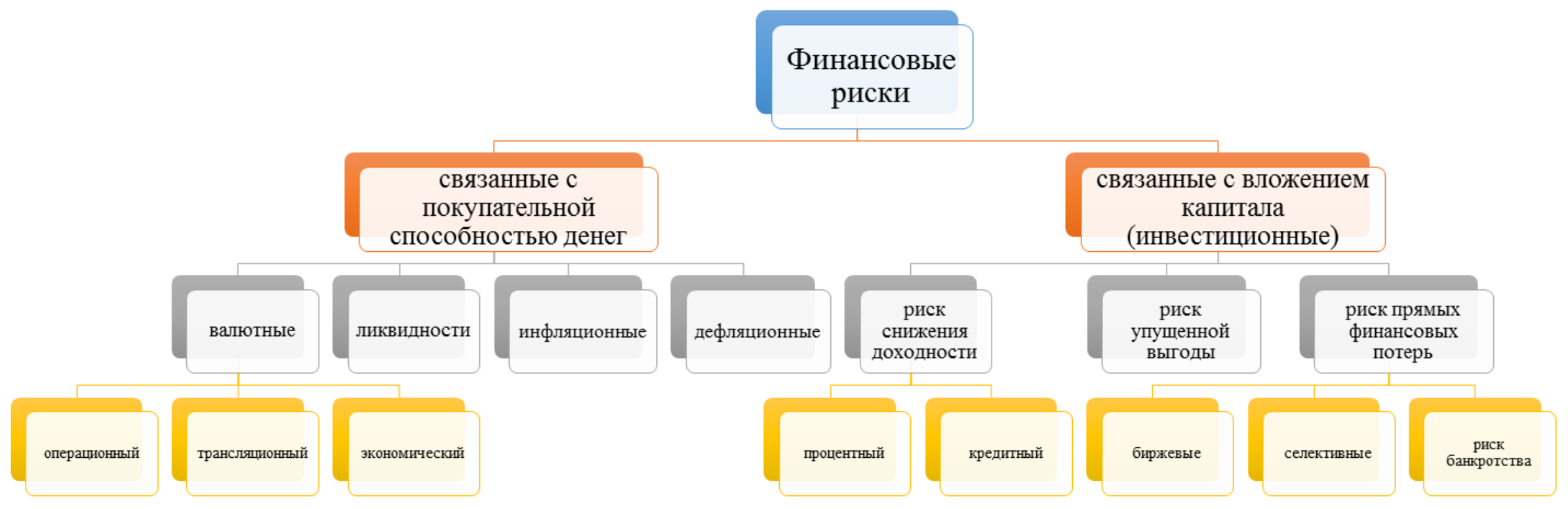

Рисунок 2 - Классификация финансовых рисков 
Транспортные риски связаны как с поставкой топлива, так и с передачей электрической и тепловой энергии к потребителям. Необходимо стремиться к снижению потерь, связанных с передачей энергии, путем улучшения качество электрических и тепловых трасс, а также с использованием логистических решений при проектировании новых станций.

Производственные риски на энергетических предприятиях могут достигать значительных величин, ведь остановка станции приведет к существенным экономическим потерям как самой станции, так и предприятий, которые не получили энергию. Однако система планово-предупредительных ремонтов, действующая на энергетических предприятиях в данный момент, в значительной степени снижает возможность аварийных ситуации, что в свою очередь снижает производственные риски.

Тем не менее, основное внимание энергетическим предприятиям необходимо обратить непосредственно на финансовые риски, ведь отсутствие собственного топлива в достаточном количестве привело к зависимости отрасли от импортируемого топлива, оплата за которое производится в иностранной валюте. Соответственно валютный риск имеет огромное значение для функционирования энергетических предприятий.

Расчет за потребленную тепловую и электрическую энергию имеет свою специфику, так как сначала происходит потребление, а лишь затем происходит оплата за потребленную энергию. Таким образом, на предприятиях энергетики возникает значительная частота кассовых разрывов, достигающая своего пика в период отопительного сезона. Такая особенность расчетов приводит к возникновению как кредитного (в случае неоплаты за потребленную энергию), так и инфляционного риска. Отсрочка платежа означает, что инфляционные процессы будут иметь значительное влияние на финансовое состояние энергетических предприятий.

Старение основных средств, приводит к необходимости их постоянного обновления. Учитывая нестабильное финансовое положение энергетических предприятий и недостаточность инвестируемых средств, возникает необходимость в заемных денежных средствах. И, как результат, сильная закредитованность энергетики приводит к большому значению процентных рисков.

Однако отраслевую специфику предприятия необходимо учитывать не только на стадии определения рисков, но и на последующих стадиях управления рисками предприятия.

После определения перечня наиболее значимых рисков следует определить их уровень. Уровень финансового риска характеризует вероятность его возникновения под воздействием определенного фактора риска (или группы таких факторов) и возможных финансовых потерь при наступлении рискового события. [5]

Исходя из указанного определения, формируются методики оценки уровня риска, которые позволяют решать конкретные задачи управления финансовой деятельностью предприятия. Так, И.А. Бланком [5] разработана следующая дифференциация методических подходов к оценке уровня риска в процессе финансового риск-менеджмента (рисунок 3$)$.

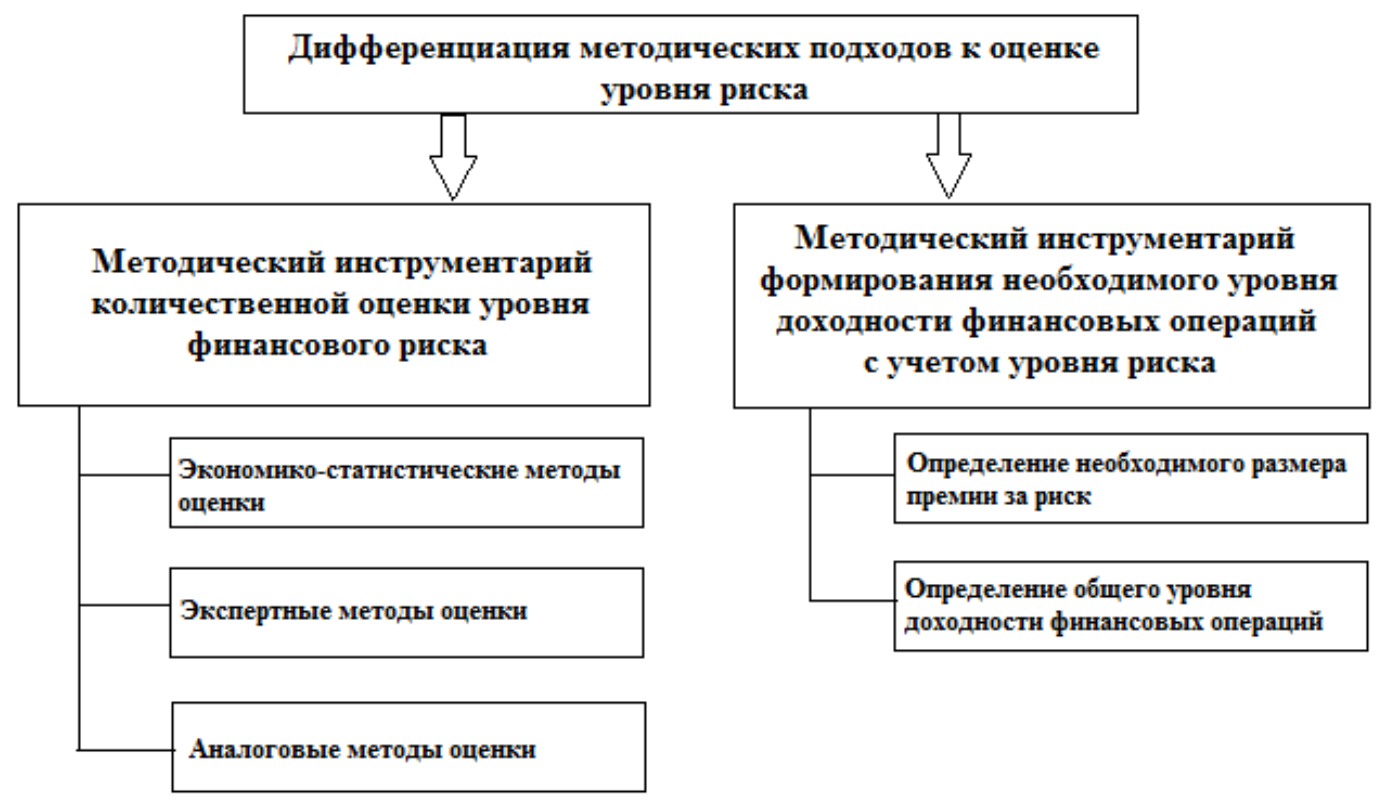

Рисунок 3 - Систематизация основных методических подходов к оценке уровня риска

Методический инструментарий количественной оценки уровня финансового риска является наиболее обширным, так как включает в себя разнообразные экономико-статистические, экспертные, аналоговые методы осуществления такой оценки. Выбор конкретных методов оценки определяется наличием необходимой информационной базы и уровнем квалификации менеджеров.

1. Экономико-статистические методы составляют основу проведения оценки уровня финансового риска. К числу основных расчетных показателей такой оценки относятся:

а) Уровень финансового риска. Он характеризует общий алгоритм оценки этого уровня, представленный следующей формулой: 
$\mathrm{YP}=\mathrm{BP} \cdot \mathrm{P \Pi}$

где $\quad$ УР - уровень соответствующего финансового риска;

ВР - вероятность возникновения данного финансового риска;

РП - размер возможных финансовых потерь при реализации данного риска.

В практике использования этого алгоритма размер возможных финансовых потерь выражается обычно абсолютной суммой, а вероятность возникновения финансового риска - одним из коэффициентов измерения этой вероятности (коэффициентом вариации, бета-коэффициентом и др.). Соответственно уровень финансового риска при его расчете по данному алгоритму будет выражен абсолютным показателем, что существенно снижает базу его сравнения при рассмотрении альтернативных вариантов.

б) Дисперсия. Она характеризует степень колеблемости изучаемого показателя (в данном случае - ожидаемого дохода от осуществления финансовой операции) по отношению к его средней величине. Расчет дисперсии осуществляется по следующей формуле:

$$
\sigma^{2}=\sum_{i=1}^{n}\left(R_{i}-\bar{R}\right)^{2} \cdot P_{i}
$$

где $\sigma^{2}$ - дисперсия;

$R_{i}$ - конкретное значение возможных вариантов ожидаемого дохода по рассматриваемой финансовой операции;

$\bar{R}$ - среднее ожидаемое значение дохода по рассматриваемой финансовой операции;

$\mathrm{P}_{\mathrm{i}}$ - возможная частота (вероятность) получения отдельных вариантов ожидаемого дохода по финансовой операции;

$\mathrm{n}$ - число наблюдений.

в) Среднеквадратическое (стандартное) отклонение. Этот показатель является одним из наиболее распространенных при оценке уровня индивидуального финансового риска, так же как и дисперсия определяющий степень колеблемости и построенный на ее основе. Он рассчитывается по следующей формуле:

$$
\sigma=\sqrt{\sum_{i=1}^{n}\left(R_{i}-\bar{R}\right)^{2} \cdot P_{i}}
$$

где $\sigma$ - среднеквадратическое (стандартное) отклонение.

г) Коэффищиент вариации. Он позволяет определить уровень риска, если показатели среднего ожидаемого дохода от осуществления финансовых операций различаются между собой. Расчет коэффициента вариации осуществляется по следующей формуле:

$$
C V=\frac{\sigma}{\bar{R}}
$$

где $\mathrm{CV}$ - коэффициент вариации.

д) Бета-коэффициент (или бета). Он позволяет оценить индивидуальный или портфельный систематический финансовый риск по отношению к уровню риска финансового рынка в целом. Этот показатель используется обычно для оценки рисков инвестирования в отдельные ценные бумаги.

Данный показатель не может иметь применения у энергетических предприятий, так как деятельность таких предприятий не подразумевает торговлю на рынке ценных бумаг.

2. Экспертные методы оценки уровня финансового риска применяются в том случае, если на предприятии отсутствуют необходимые информативные данные для осуществления расчетов экономико-статистическими методами. Эти методы базируются на опросе квалифицированных специалистов (страховых, финансовых, инвестиционных менеджеров соответствующих специализированных организаций) с последующей математической обработкой результатов этого опроса.

В целях получения более развернутой характеристики уровня риска по рассматриваемой операции опрос следует ориентировать на отдельные виды финансовых рисков, идентифицированные по данной операции (процентный, валютный, инвестиционный и т.п.).

В процессе экспертной оценки каждому эксперту предлагается оценить уровень возможного риска, основываясь на определенной балльной шкале, например:

$\begin{array}{ll}\text { риск отсутствует: } & 0 \text { баллов; } \\ \text { риск незначительный: } & 10 \text { баллов; } \\ \text { риск ниже среднего уровня: } & 30 \text { баллов; } \\ \text { риск среднего уровня: } & 50 \text { баллов; } \\ \text { риск выше среднего уровня: } & 70 \text { баллов; } \\ \text { риск высокий: } & 90 \text { фаллов; } \\ \text { риск очень высокий: } & 100 \text { баллов. }\end{array}$


Так как в подобном анализе участвует значительное количество экспертов, то необходимо проверить полученные данные на согласованность. Для проверки результатов можно использовать коэффициент конкордации Кендэлла $W$, учитывающий разброс от среднего уровня:

$$
W=\frac{12 \cdot S}{m^{2} \cdot\left(n^{3}-n\right)}
$$

где $S$ - сумма квадратов отклонений суммы рангов от средней их суммы;

$\mathrm{m}$ - количество экспертов;

$\mathrm{n}$ - количество оцениваемых рисков.

Коэффициент конкордации $W$ может изменяться от 0 до 1 . Если $W=0$, то согласованности между экспертными оценками нет, если $W=1$ существует полная согласованность экспертов в оценке факторов.

3. Аналоговые методы оценки уровня финансового риска позволяют определить уровень рисков по отдельным наиболее массовым финансовым операциям предприятия. При этом для сравнения может быть использован как собственный, так и внешний опыт осуществления таких финансовых операций. [5]

Анализ рисков является одним из самых сложных этапов управления. Он подразделяется на два дополняющих друг друга вида: качественный и количественный анализ.

Главной задачей качественного анализа является определение факторов риска, этапов и работ, при выполнении которых он возникает.

Количественный анализ означает численное определение размеров рисков отдельных мероприятий и проекта в целом. [2]

Таким образом, целесообразно отнести метод экспертных оценок не к количественному анализу, а к качественному.

Еще одним из методов качественного анализа рисков является графический метод.

При определении частоты возникновения некоторого уровня потерь от рисков следует найти ее значение как можно в большем количестве точек (т.е. при различных уровнях потерь). Обычно сделать это оказывается достаточно сложно. Поэтому необходимо определить значения рассматриваемого показателя хотя бы в четырех основных точках. Выделяют четыре основные области риска, которые должны принимать во внимание менеджеры по риску.

Безрисковая область. Для этой области характерным является отсутствие потерь при совершении операций и получении как минимум расчетной прибыли. Левая граница безрисковой области проходит через точку А - размер расчетной прибыли, правая граница отсутствует, поскольку теоретически прибыль предприятия не ограничена.

Область допустимого риска. Она характеризуется уровнем потерь, не превышающим размеры расчетной прибыли. В этой области еще возможно осуществление данного решения, поскольку предприятие рискует только тем, что в результате своей деятельности оно в худшем случае просто не получит прибыль, а все произведенные затраты окупятся.

Область недопустимого риска. В границах этой области возможны потери, величина которых превышает размер расчетной прибыли, но не больше общего размера расчетной выручки. Такой уровень риска недопустим, поскольку предприятие подвергается опасности потерять всю свою выручку при реализации данного решения, а это будет означать, что оно произвело бессмысленные затраты не только времени, но и денежных средств.

Область критического риска. Это самая опасная зона, в которой возможные потери грозят сравниться с величиной собственных средств предприятия. Область критического риска ассоциируется с понятием банкротства, а поэтому ни при каких условиях нельзя допускать такой уровень риска.

Построим график зависимости между размером потерь и частотой их возникновения. Полученная кривая будет фактически отражать соотношение величины потерь и вероятности их возникновения. Допустим, что с вероятностью 0,55 потери будут равны размеру расчетной прибыли $\left(\mathrm{S}_{1}\right)$, с вероятностью 0,2 - величине, равной расчетной выручки $\left(\mathrm{S}_{2}\right)$ и с вероятностью 0,05 - величине, равной размеру собственных средств $\left(\mathrm{S}_{3}\right)$ (рисунок 4$)$.

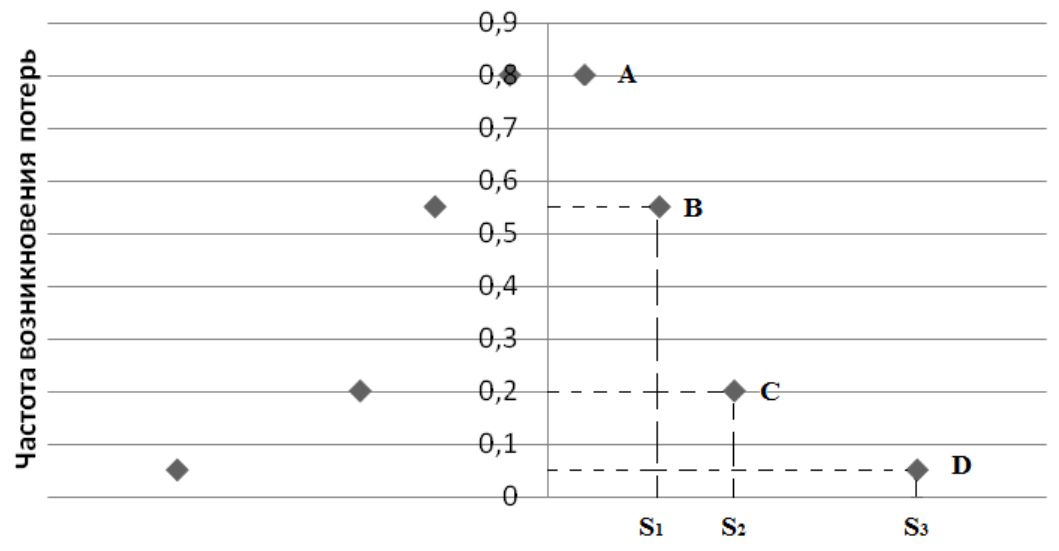

Возможные потери

Рисунок 4 - Построение кривой риска 
Рассматривая рисунок, нетрудно определить, что участок АВ кривой будет находиться в области допустимого риска, участок ВC - в области недопустимого риска, а участок CD - в области критического риска. К области критического риска будет относиться и участок кривой, находящийся за точкой $\mathrm{D}$, т.е. за пределом уровня банкротства предприятия. Однако стоит понимать, что для каждого риска данная кривая будет иметь свои точки. [6]

Стоит отметить, что методический инструментарий количественной оценки уровня финансового риска не может полностью быть применим для энергетических предприятий. В виду существующей организационно-правовой формы организации предприятий энергетики, отпадает необходимость использования методического инструментария формирования необходимого уровня доходности финансовых операций с учетом уровня риска.

В то же время, специфика деятельности предприятий энергетики, которая носит как социальный, так и экономикообразующий характер, приводит к необходимости строгого контроля качества производимой тепловой и электрической энергии.

Качество отпускаемой электрической и тепловой энергии и возможные отклонения регламентированы ГОСТ 13109-97 «Электрическая энергия. Нормы качества электрической энергии в системах электроснабжения общего назначения».

Качественными показателями электроэнергии как товара являются частота и напряжение, синусоидальность переменного тока. Качественными показателями тепловой энергии являются температура и давление.

Надежность (применительно к электроэнергетической системе) - способность обеспечить поставку заявленной потребителем, в соответствии с договором энергоснабжения, электрической энергии (мощности) при выполнении потребителем всех договорных технических (условия присоединения к электрической сети и торговой системе) и коммерческих (оплата) обязательств, а также при соблюдении поставщиком установленных договором с потребителем технических условий поставки в отношении качественных и количественных показателей надежности и качества поставляемой электроэнергии (мощности).

Надежность энергоснабжения потребителей характеризуется:

- непрерывностью энергоснабжения в любой ситуации;

- исполнением требований по количеству и качеству поставляемых энергоносителей.

Совпадение во времени процессов производства, передачи и потребления энергии и невозможность работы «на склад» являются важнейшими особенностями энергетики. В этих условиях надежность энергоснабжения со стороны генерации обеспечивается созданием резервной мощности (а не запасов продукции, как на других предприятиях), созданием запасов топлива на ТЭС и запасов воды в водохранилищах ГЭС и ГАЭС, в сфере передачи энергии - строительством резервных сетевых объектов, у потребителей - созданием резервных источников питания.

Резерв генерирующей мощности - это дополнительная генерирующая мощность, которая может быть введена в работу за определенный период времени.

Коэффициент резерва генерирующей мощности энергосистемы определяется из следующего выражения:

$K_{\text {рез }}=\frac{\left(N_{\max \text { доcm }}-P_{\max }\right)}{P_{\max }}$

где $\quad N_{\max }$ дост - максимально доступная мощность энергосистемы;

$P_{\max }$ - максимальная нагрузка энергосистемы.

В энергосистемах создается единый диспетчерский резерв мощности, который группируется по функциональному назначению и маневренности. [7]

Процесс контроля качества отпускаемой энергии - это специфический технический процесс, осуществляемый с помощью средств автоматики. Несоблюдение основных параметров качества энергии может быть вызвано как внутренними (соблюдение технического регламента, изношенность объектов), так и внешними причинами (природные катаклизмы), но всегда ведет к потерям как для потребителя, так и для предприятий энергетики. Таким образом, если энергия не соответствует предусмотренным стандартам, то это в большинстве случаев приведет к финансовым потерям. Учет данной специфики энергетических предприятий будет особенно важен на этапе расчета величины производственного риска.

\section{ВЫВОДЫ}

В связи с изменениями, которые претерпевает на данном этапе энергетика Республики Беларусь, финансовые риски станут новым видом рисков для энергетических предприятий, так как предприятия будут вынуждены снизить уровень государственной поддержки и самостоятельно функционировать в рыночных условиях. Величина данных рисков может в значительной степени повлиять на финансовое состояние любого предприятия.

Целевые ориентиры хозяйственной деятельности предприятия необходимо в каждом конкретном случае выбирать на основе подробного анализа составляющих внешней и внутренней среды. Поскольку внешняя среда в условиях трансформационной экономики республики крайне динамичная, то каждый из субъектов стремится ориентироваться на гибкие стратегии развития, четко реагируя на разнообразные факторы внешнего окружения, сохраняя при этом устойчивость функционирования. 
Разработка программы управления рисками на уровне предприятия должна обеспечивать такое управление, при котором основным элементам структуры и этапам деятельности предприятия обеспечиваются высокая устойчивость и защищенность от внутренних и внешних рисков.

Учитывая специфику деятельности, стоит отметить, что производственные риски на энергетических предприятиях могут достигать очень больших величин, ведь остановка станции приведет к значительным экономическим потерям как самой станции, так и предприятий, которые не получили энергию.

В энергетике не всегда возможно заранее дать точную количественную оценку рискам, а методы определения её степени еще не отработаны. В связи с этим возникают трудности в сфере минимизации рисков и оценки затрат на управление ими. Особое значение при этом отводится разработке и реализации методов и инструментов оценки и управления рисками. Процесс разработки данных методов и инструментов должен проходить с учетом всех специфических особенностей энергетических предприятий.

\section{ЛИТЕРАТУРА}

1. Шапкин А.С. Теория риска и моделирование рисковых ситуаций: Учебник для бакалавров / А.С. Шапкин, В.А. Шапкин. - 6-е изд. - М.: Издательско-торговая корпорация «Дашков и Ко», 2014. - 880 с. $271 \mathrm{c}$.

2. Титович, А.А. Менеджмент риска и страхования : учеб. пособие / А.А. Титович. - Минск : Выш. шк., 2008. -

3. Редина М.М. Эколого-экономическая диагностика устойчивости предприятий нефтегазового комплекса. - М.: РУДН, 2011. - 170 с. 4. Стандарты Управления Рисками Великобритании / Пер. с англ. FERMA [Электронный ресурс] - Режим доступа - http://www.rrms.ru/ - Дата доступа 05.02.2015.

4. Балабанов И.Т. Риск-менеджмент. - М.: Финансы и статистика, 1996.

5. Бланк И.А. Управление финансовыми рисками. - К.: Ника-Центр, 2005. - 600с.

6. Тымуль Е.И. Графическая интерпретация оценки риска / Е.И. Тымуль // Сборник научных статей студентов, аспирантов, магистрантов. - 2015. - № 13 - Том 2 - с.277-279.

7. Экономика и управление в энергетике: учебник для магистров / под общ. ред. Н.Г. Любимовой, Е.С. Петровского. - М. : Издательство Юрайт, 2014. - 485 с.

Статья поступила в редакиию 7 июля 2015 года. 